\title{
UbcH7 interacts with the glucocorticoid receptor and mediates receptor autoregulation
}

\author{
Helen Garside, Charlotte Waters, Andy Berry, Lisa Rice, Helen C Ardley ${ }^{1}$, Anne White, Philip A Robinson ${ }^{1}$ \\ and David Ray \\ Endocrine Sciences Research Group and Centre for Molecular Medicine, Faculty of Medicine, University of Manchester, Stopford Building, Oxford Road, \\ Manchester M13 9PT, UK \\ ${ }^{1}$ Molecular Medicine Unit, CSB, St. James's University Hospital, University of Leeds, Leeds LS9 7TF, UK \\ (Requests for offprints should be addressed to D Ray; Email: david.w.ray@man.ac.uk)
}

\begin{abstract}
Unlike other nuclear receptors, transactivation by the glucocorticoid receptor (GR) is increased by the inhibition of the ubiquitin/proteasome pathway. Here, we demonstrate that the ubiquitin-conjugating enzyme (E2), $\mathrm{UbcH} 7$, physically interacts with the GR and, when overexpressed, reduces the ability of the receptor to upregulate gene expression. Chemical inhibition of the $26 \mathrm{~S}$ proteasome abolished the downregulation effect of overexpressed $\mathrm{UbcH} 7$, suggesting a role for the $26 \mathrm{~S}$ proteasome, and GR protein stability in mediating the $\mathrm{UbcH} 7$ effect. Furthermore, a $\mathrm{UbcH} 7$ dominant negative mutant (C89S), unable to transfer ubiquitin, failed to repress GR
\end{abstract}

transactivation. Indeed, overexpression of the mutant $\mathrm{UbcH} 7$ was sufficient to augment GR transactivation to levels achieved using the proteasome inhibitor MG132, but there was no further induction when MG132 and the $\mathrm{UbcH7}$ mutant were used together. Expression of the dominant negative $\mathrm{UbcH} 7$ abolished ligand-dependent downregulation of GR protein, suggesting that the $\mathrm{UbcH7}$ effect was mediated by regulation of GR protein concentration. Taken together, these data show that $\mathrm{UbcH7}$ is a key regulator of GR turnover and glucocorticoid sensitivity.

Journal of Endocrinology (2006) 190, 621-629

\section{Introduction}

The glucocorticoid receptor (GR) is a member of the nuclear receptor superfamily. It is a key regulator of many homeostatic mechanisms and is also the target of therapeutic glucocorticoids used to treat inflammatory diseases. Much is now understood about the structure and function of the GR. The activated receptor is capable of both up- and downregulating target gene expressions. It acts through interaction with many other transcription factors and co-modulator proteins. Cellular glucocorticoid sensitivity is not only related to receptor expression; in most cell types GR expression is also negatively regulated by exposure to glucocorticoid hormones.

Upon ligand binding, the GR translocates from the cytoplasm to the nucleus where it binds to specific DNA sequences termed glucocorticoid-response elements (GREs) to regulate target gene transcription. A number of studies have shown that cellular sensitivity to glucocorticoids is influenced by glucocorticoid receptor density (Cidlowski \& Cidlowski 1981, Vanderbilt et al. 1987, Hoeck et al. 1989, Silva et al. 1994) with ligand-binding initiating a process of glucocorticoid receptor downregulation. This ligand-dependent receptor downregulation is mediated both at the level of gene transcription as well as protein stability (Svec \& Rudis 1981, McIntyre \& Samuels 1985, Dong et al. 1988, Vedeckis et al. 1989, Oakley \& Cidlowski 1993).

The GR is subject to a number of post-translational modifications, which include phosphorylation and ubiquitylation. Activation of the receptor by ligand binding initiates $N$-terminal phosphorylation (Weigel 1996, Bodwell et al. 1998). The phosphorylation state of proteins can regulate their stability (Webster et al. 1997), by targeting the protein for polyubiquitylation and subsequent degradation via the 26 S proteasome (Fuchs et al. 1998, Kornitzer \& Ciechanover 2000, Wallace \& Cidlowski 2001, Deroo et al. 2002). The recognition of a phosphorylated substrate relies on its interaction with a specific ubiquitin-protein ligase (E3). Protein ubiquitylation is an energy-dependent process, which requires sequential transfer of ubiquitin from an ubiquitinactivating enzyme (E1), to an ubiquitin-conjugating enzyme (E2) to target protein generally facilitated by an E3. Ubiquitylation of the GR is regulated by at least three different E3s: CHIP (Connell et al. 2001, Wang \& DeFranco 2005), E6-AP (Nawaz \& O'Malley 2004), and hmdm2 (human homolog of $\mathrm{mdm} 2$ ) via the formation of a trimeric complex with p53 (Sengupta \& Wasylyk 2001). 
Interestingly, inhibition of proteasomal activity decreases the ligand-induced transcriptional activities of the estrogen and thyroid hormone receptors (Dace et al. 2000, Lonard et al. 2004). This observation suggests that protein ubiquitylation of these receptors, and/or regulatory co-factors, is required for continued transcriptional activity. By contrast, chemical inhibition of the proteasome increased the ligand-induced transactivation potential of the GR, while blocking the ligand-dependent downregulation of GR levels (Wallace \& Cidlowski 2001, Wang \& DeFranco 2005). These data point to a GR-specific mode of regulation by the ubiquitinproteasome pathway. Importantly, the E3 ligase, CHIP, may determine the GR response to ubiquitylation by regulating the coupling to the ubiquitin/proteasome-dependent protein degradation pathway (Wang \& DeFranco 2005).

Recently, Perissi et al. (2004) demonstrated that the E2, $\mathrm{UbcH7}$, was recruited to DNA by activated nuclear receptors. This interaction enhanced their transcriptional activities. Moreover, UbcH7 modulated nuclear receptor transactivation, including GR function, by interaction with the co-activator SRC-1 (Verma et al. 2004). Independently, we identified $\mathrm{UbcH} 7$ as the physical interacting partner of the GR in a yeast two-hybrid screen. Here, we demonstrate that $\mathrm{UbcH} 7$ interacts directly with the GR in vitro and inhibits its transactivation function via targeting the protein for proteasome degradation. Therefore, $\mathrm{UbcH} 7$ interacts with multiple members of the nuclear receptor superfamily, and with their co-modulator proteins, but results in differential effects on their transcriptional activity depending on the model used. This may indicate the underlying differences in the mechanisms of transcriptional regulation used by these closely related proteins.

\section{Methods}

\section{Plasmids}

Full-length UbcH7 was cloned into pcDNA3-GFP to create UbcH7.pcDNA3 (Ardley et al. 2001). The UbcH7 C89S mutant was generated from $\mathrm{UbcH7}$.pcDNA3 to create C89SUbcH7.pcDNA3 using the QuikChange site-directed mutagenesis kit (Stratagene, Amsterdam, The Netherlands) according to the manufacturer's protocol (Ardley et al. 2003). Mouse mammary tumor virus long terminal repeat luciferase reporter gene (MMTV-luc) and pcDNA3-GR have been previously described (Stevens et al. 2003a, Waters et al. 2004). Cytomegalovirus (CMV)-renilla vector was obtained from Promega, and used to control the transfection efficiency as previously described (Stevens et al. 2003a,b).

\section{Yeast two-hybrid screen}

Total RNA was extracted from $1 \times 10^{9}$ untreated CORL103 cells using TRIzol reagent (GIBCO BRL). An mRNA was isolated from $3 \mathrm{mg}$ total RNA using GenElute
mRNA isolation (SIGMA), according to the manufacturer's guidelines. A cDNA library was constructed in B42 AD vector of the MATCHMAKER LexA hybrid screen system (Clontech) using the restriction endonucleases EcoRI and Xhol to ensure the correct orientation of the insert cDNA using the cDNA synthesis kit as per the manufacturer's instruction (Stratagene). This library formed the 'prey' for the yeast two-hybrid screen. Construction of the GR 'bait' construct (LexA-GR ${ }_{525-777}$ ) was previously described (Stevens et al. 2003a).

Saccharomyces cerevisiae (EGY48) were sequentially transformed with reporter, bait, and then prey DNA constructs. Transformations were performed using a standard lithium acetate procedure (Stevens et al. 2003a). The transfected yeast cells were replica-plated onto synthetic dropout/Gal/ Raf plates with X-gal, containing the appropriate treatment (50 $\mu \mathrm{M}$ RU486 (mifepristone) or dimethylsulfoxide vehicle as the solvent control). The cDNA library plasmid DNA was isolated from positive colonies and re-introduced into fresh $S$. cerevisiae to confirm a positive interaction between the C-terminus of the GR $\left(\mathrm{GR}_{525-777}\right)$ and prey. Positive prey DNA were isolated, sequenced, and identified using BLAST.

\section{Immunoprecipitation}

Cells were lysed in radioimmunoprecipitation assay buffer (RIPA) buffer $(50 \mathrm{mM}$ Tris- $\mathrm{HCl}$ buffer $(\mathrm{pH} 7 \cdot 4)$ containing $1 \%(\mathrm{v} / \mathrm{v}) \mathrm{NP}-40,0 \cdot 25 \%(\mathrm{w} / \mathrm{v})$ sodium deoxycholate, $150 \mathrm{mM} \mathrm{NaCl}, 1 \mathrm{mM}$ EDTA, and complete proteaseinhibitor cocktail). Protein concentration was determined using the Bio-Rad Bradford assay reagent. Total cellular lysate protein, $500 \mu \mathrm{g}$, was incubated with $2 \cdot 0 \mu \mathrm{g}$ antibodies and $50 \mu \mathrm{l}$ resuspended protein A agarose beads (Santa Cruz Biotechnology, Santa Cruz, USA) for $16 \mathrm{~h}$ at $4{ }^{\circ} \mathrm{C}$ on a tube rotator. The beads were captured by centrifugation, and washed thrice in RIPA buffer. The bound proteins were released by boiling in SDS-PAGE loading buffer for $5 \mathrm{~min}$.

\section{Immunoblotting}

GR (M20; Santa Cruz; Waters et al. 2004), UbcH7 (Ardley et al. 2003), and $\beta$-actin (Sigma; anti-actin) antibodies were employed. Samples were resolved on SDS-PAGE gels, and transferred onto nitrocellulose membranes (Bio-Rad). Membranes were blocked for $6 \mathrm{~h}$ with $5 \%(\mathrm{w} / \mathrm{v})$ non-fat dry milk in Tris-buffered saline with $0 \cdot 05 \%(\mathrm{v} / \mathrm{v})$ Tween 20 and incubated for $16 \mathrm{~h}$ with either M20 (1:2000), UbcH7 $(1: 3000)$ or $\beta$-actin $(1: 2000)$ primary antibodies diluted in blocking buffer. The membranes were washed thrice, and blotted with secondary antibody conjugated with horseradish peroxidase. After three more washes, the membrane was developed with Pierce Supersignal West Pico reagent. Membranes were subsequently stripped and blotted for $\beta$-actin to confirm equal loading of samples and transfer of protein. 


\section{Transfection}

COS7 cells, and HeLa cells were cultured in Dulbecco's modification of Eagle's medium (DMEM) with Glutamax-1 (Invitrogen Life Technologies), and 10\% (v/v) fetal calf serum before being seeded at $5 \times 10^{5}$ cells $/ 10 \mathrm{~cm}$ tissue culture dish. All transfections were performed using Fugene 6 according to the manufacturers' instructions (Roche). For glucocorticoid reporter gene studies, cells were transfected with $2 \cdot 0 \mu \mathrm{g}$ MMTV-luc, $0 \cdot 5 \mu \mathrm{g}$ pcDNA3-GR, $0 \cdot 3$ or $1 \cdot 0 \mu \mathrm{g}$ pcDNA3$\mathrm{UbcH7}-\mathrm{GFP}$ or empty vector control, and $0 \cdot 2 \mu \mathrm{g}$ CMVRenilla. Post-transfection cells were transferred to DMEM with Glutamax-1 and 10\% (v/v) charcoal/dextran-stripped calf serum, divided into 24-well plates and treated in triplicate with steroid for $18 \mathrm{~h}$ before harvest. For chemical inhibition of the proteasome, cells were transfected with $2 \cdot 0 \mu \mathrm{g}$ MMTV-luc, $0.5 \mu \mathrm{g}$ pcDNA3-GR, $1.0 \mu \mathrm{g}$ pcDNA3-UbcH7-GFP, the C89S.UbcH7 mutant or the empty vector control, and $0 \cdot 2 \mu \mathrm{g}$ CMV-Renilla. Cells were then transferred into $10 \%$ (v/v) charcoal/dextran-stripped fetal calf serum containing media and split into 12 -well plates. They were then pre-treated for $1 \mathrm{~h}$ with $1 \cdot 0 \mu \mathrm{M} \mathrm{MG}-132$ (Calbiochem) or vehicle then with $100 \mathrm{nM}$ dexamethasone as appropriate. Cell lysates were subjected to dual luciferase assay as per the manufacturer's instructions (Promega). Firefly luciferase results were normalized using renilla luciferase as control for differences in transfection efficiency. All transfections were performed on at least three occasions with similar results.

\section{UbcH7 localization}

COS7 cells were sedimented, resuspended in medium supplemented with $5 \%(\mathrm{v} / \mathrm{v})$ charcoal/dextran-stripped serum (Hyclone, UK) and seeded onto $22 \mathrm{~mm}$ glass coverslips at a density of $3 \times 10^{5}$ cells/slide. After $24 \mathrm{~h}$, cells were transfected with $0.5 \mu \mathrm{g}$ pcDNA3-GR and either $0.5 \mu \mathrm{g}$ $\mathrm{UbcH} 7$-green fluorescent protein (GFP) or $0.5 \mu \mathrm{g}$ C89SGFP using Fugene 6 (Roche). Eighteen hours posttransfection, cells were treated with vehicle (dimethylsulphoxide; DMSO) or dexamethasone (100 $\mathrm{nM})$ for $1 \mathrm{~h}$ before fixing with $4 \%(\mathrm{w} / \mathrm{v})$ paraformaldehyde. To visualize the GR, cells were then washed thrice with tris buffered saline (TD) buffer $(10 \mathrm{mM}$ Tris- $\mathrm{HCl}$ buffer $(\mathrm{pH} 8 \cdot 0)$ containing $150 \mathrm{mM}$ $\mathrm{NaCl}$ ) and treated with blocking buffer (TD plus $1 \%(\mathrm{w} / \mathrm{v})$ BSA, $0 \cdot 2 \%(\mathrm{v} / \mathrm{v})$ Triton $\mathrm{X}-100)$ for $1 \mathrm{~h}$ at $20^{\circ} \mathrm{C}$. A 1:200 dilution of primary antibody, P20 sc-1002 (Santa Cruz) in washing buffer (TD plus $1 \%(\mathrm{w} / \mathrm{v}) \mathrm{BSA}, 0 \cdot 05 \%(\mathrm{v} / \mathrm{v})$ Triton $\mathrm{X}-100)$, was added for $2 \mathrm{~h}$ at $20^{\circ} \mathrm{C}$. Cells were then washed thrice with wash buffer. A 1:200 dilution of the appropriate secondary antibody (Alexa Fluor 568 goat anti-rabbit IgG; Molecular Probes, Eugene, OR, USA) in washing buffer was added for $1 \mathrm{~h}$ at $20^{\circ} \mathrm{C}$. The cells were then washed thrice and mounted on slides using Citifluor (glycerol/PBS; Citifluor Ltd, UK). The coverslips were sealed and stored at $4{ }^{\circ} \mathrm{C}$. Images were taken using a Leica TCS-4D confocal microscope (Leica Microsystems, Heidelberg, Germany) using a $63 \times$ water immersion objective. To visualize Alexa 568, cells were viewed using an excitation filter of $568 \mathrm{~nm}$ and the emission was collected using a $590 \mathrm{~nm}$ long pass filter. To visualise GFP, cells were excited with an argon laser at $488 \mathrm{~nm}$ and emission was collected using a band-pass filter of $525 \pm 25 \mathrm{~nm}$.

\section{Statistical analysis}

Comparison of group data was done by ANOVA followed by Bonferroni $t$-test. Significance was taken as $<0 \cdot 05$, and all significant differences found are marked on the graphs. The package SPSS for windows $11 \cdot 5$ was used for analysis.

\section{Results}

\section{Identification of $\mathrm{UbcH7}$ as a GR-interacting protein}

We used the C-terminal domain of the GR (amino acid residues 525-777) to screen a yeast two-hybrid library generated from the human small cell lung cancer cell line CORL103. We were interested in finding proteins that interacted in the presence of the GR antagonist RU486. Fifteen clones were identified as interacting with the GR bait in the presence of RU486. Interactions were confirmed in re-transformed yeast cells. Clones were sequenced, and revealed that one, XP15, had $100 \%$ identity with residues 41-154 of the coding sequence of $\mathrm{UbcH} 7$. The interaction between XP15 and the GR was strongest in the presence of RU486. These results identify $\mathrm{UbcH7}$ as interacting with the C-terminus of the GR.

\section{In vivo interaction between the $\mathrm{GR}$ and $\mathrm{UbcH} 7$}

We studied the interaction between $\mathrm{UbcH} 7$ and the GR in COS7 cells in order to ensure that binding also occurred under physiological conditions in mammalian cells. These cells were chosen for two reasons. First, we demonstrated that transfected GR levels were reduced when the cells were cultured in the presence of glucocorticoid (Fig. 1a), and second that they expressed endogenous $\mathrm{UbcH} 7$ (Fig. 1b).

The addition of glucocorticoid produced no change in the levels of either endogenous $\mathrm{UbcH} 7$, or $\mathrm{UbcH7}$-GFP or dominant negative (C89S).UbcH7-GFP in transfected COS7 cells (Fig. 1b). Therefore, the mechanism of action of glucocorticoid is not through a modulation of $\mathrm{UbcH} 7$ levels.

Immunoprecipitation with GR antibodies of COS7 cell lysates previously transfected with either UbcH7-GFP or C89S.UbcH7-GFP was followed by immunoblotting for $\mathrm{UbcH7}$. Initial studies performed in the absence of MG-132, the $26 \mathrm{~S}$ proteosome inhibitor, or dominant negative $\mathrm{UbcH} 7$, did not show co-immunoprecipitated $\mathrm{UbcH} 7$ with the GR. $\mathrm{UbcH7}$ was only detected in lysates prepared from those cells transfected with the C89S.UbcH7-GFP construct, and co-incubated with MG-132. These levels were enhanced in the presence of dexamethasone (Fig. 1c). Cells were 
(a)

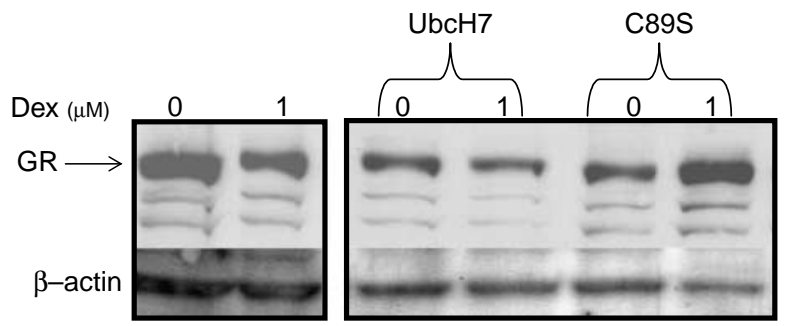

(b)

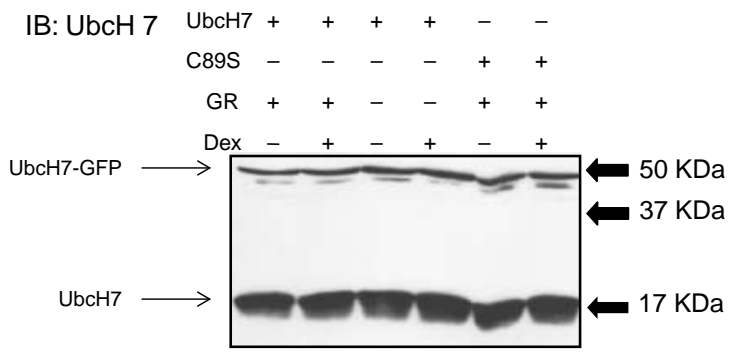

(c)

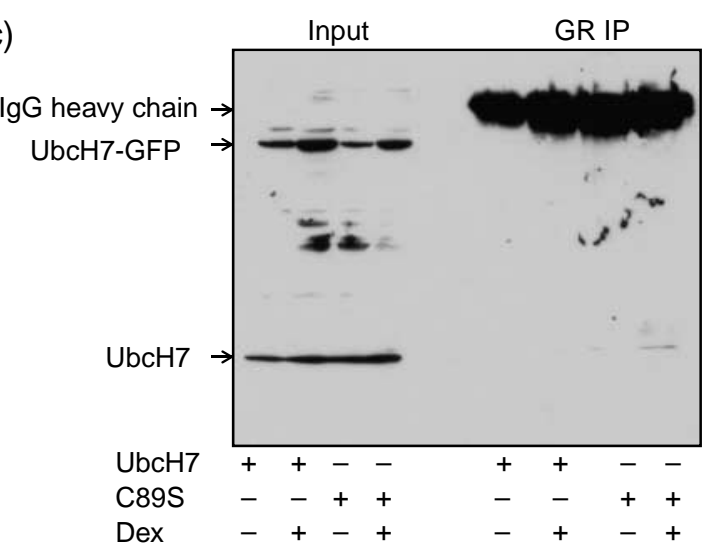

Figure 1 In vivo interactions between glucocorticoid receptor (GR) and UbcH7. (a) COS7 cells were transfected with the GR pcDNA3 expression vector, or UbcH7-GFP, or C89S-GFP as indicated, and cultured in the presence of $1.0 \mu \mathrm{M}$ dexamethasone for $18 \mathrm{~h}$ before harvest. Western blot analysis was then performed on cell lysates for GR protein expression. The immunoblot of whole cell lysate was subsequently stripped and re-probed for $\beta$-actin to ensure approximately equal loading of protein. (b) COS7 were transfected with the GR pcDNA3 expression vector and either wildtype $(\mathrm{UbcH} 7)$, or dominant negative $\mathrm{UbcH} 7$ (C89S), and then incubated with (+) or without (-) $1 \mu \mathrm{M}$ dexamethasone (Dex) for $18 \mathrm{~h}$ before harvest. Cell lysates were analysed for $\mathrm{UbcH} 7$ protein expression by western blot analysis. The presence of higher molecular weight bands indicates the expression of UbcH7-GFP or C89S.UbcH7-GFP (both marked UbcH7-GFP), whereas the lower bands represent endogenous $\mathrm{UbcH} 7$ (marked $\mathrm{UbcH}$ ). The immunoblot was subsequently stripped and re-probed for $\beta$-actin to confirm equal loading and transfer (not shown). (c) COS7 cells were co-transfected with the GR, and either wild-type UbcH7-GFP (UbcH7) or C89S.UbcH7-GFP (C89S), pcDNA expression constructs. The cells were then incubated with MG132 with (+) or without (-) $1.0 \mu \mathrm{M}$ dexamethasone (Dex) as indicated for $18 \mathrm{~h}$ before harvest. The cell lysates were then immunoprecipitated with GR antibodies, before immunoblotting for $\mathrm{UbcH}$ 7. Immunoblot analysis of the input lysates are shown in the left-hand four lanes (input), the immunoblot of the GR immunoprecipitate shown on the right-hand four lanes (GR IP). The IgG heavy chain band present in the immunoprecipitates is marked. 
(a)

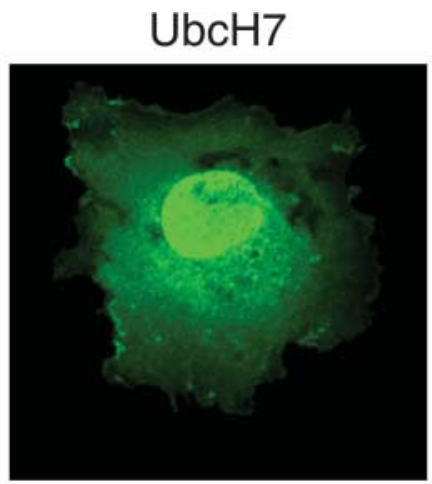

0

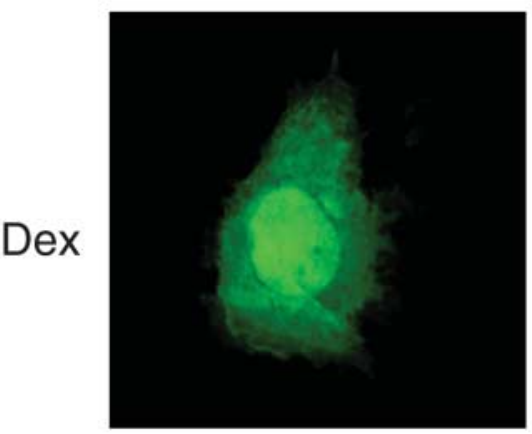

(b)
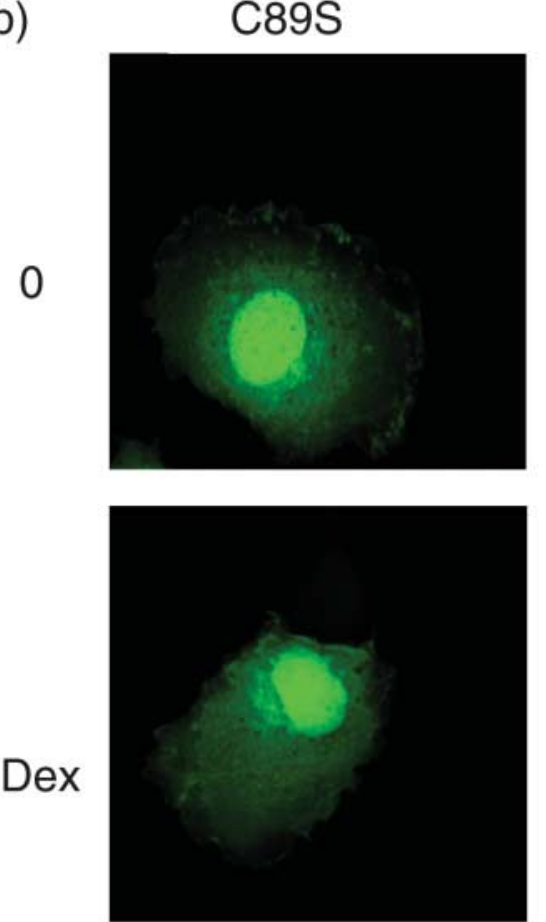
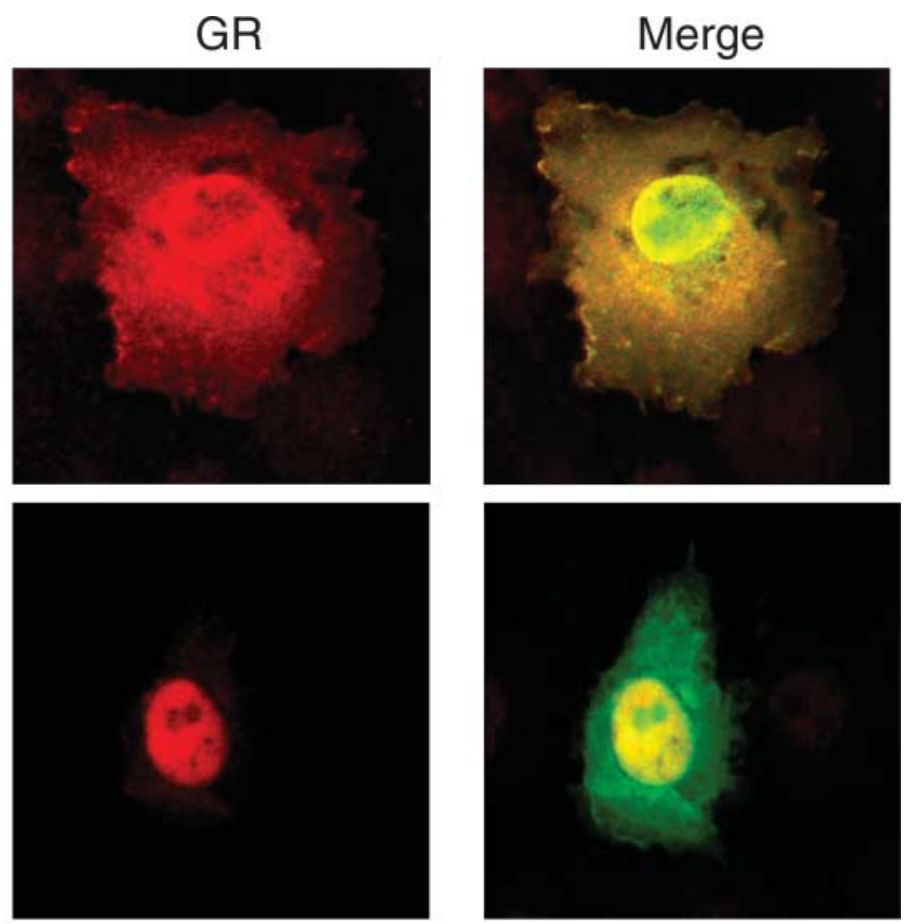

GR
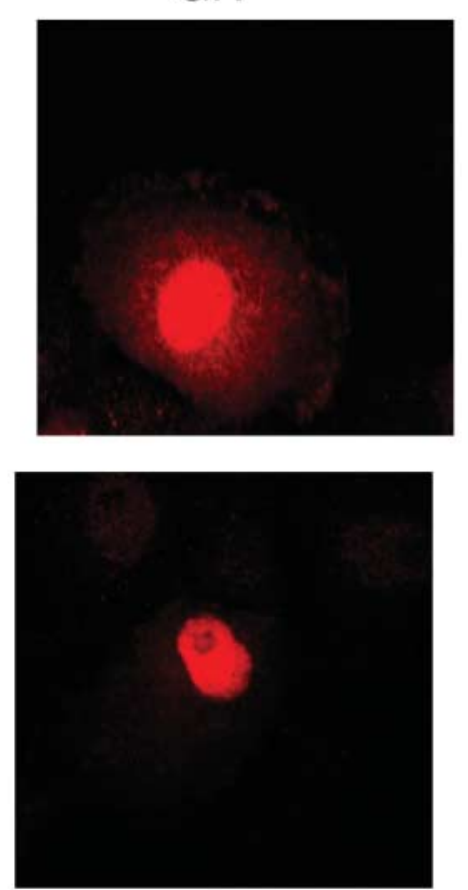

Figure 2 Co-localisation of glucocorticoid receptor (GR) and UbcH7. COS7 cells were transiently transfected with pcDNA3-GR and (a) either UbcH7-GFP or (b) C89S-GFP. Post-transfection cells were treated with $100 \mathrm{nM}$ dexamethasone (Dex) for 30 min before fixation. The GR was visual ized by immunostaining using a GR antibody and anti-rabbit Alexa 568-conjugated secondary antibody. Cells were then imaged with a Leica TCS-4D confocal microscope (Leica Microsystems, Heidelberg, Germany) using a $63 \times$ water immersion objective. To visualize Alexa 568 fluorescence, cells were viewed using an excitation filter of $568 \mathrm{~nm}$ and emission was collected using a $590 \mathrm{~nm}$ long pass filter. To visualise GFP fluorescence, cells were excited with an argon laser at $488 \mathrm{~nm}$ and emission was collected using a band-pass filter of $525 \pm 25 \mathrm{~nm}$. 
co-incubated with MG-132 to inhibit proteasomal degradation of ubiquitinated proteins.

Analysis of the effect of glucocorticoid on the localization of $\mathrm{UbcH} 7$ and GR in COS7 cells

We employed a combined immunofluorescence, transfected fluorophore procedure to examine if $\mathrm{UbcH} 7$ and GR shared an overlapping intracellular distribution. This would not only provide further evidence of interaction, but may also evidence for an interaction that was restricted to specific subcellular compartments. It would be a prerequisite for functional interaction in vivo.

An intense nuclear and relatively weaker cytoplasmic UbcH7 expression was noted in COS7 cells transfected with the UbcH7-GFP (Fig. 2a). The localization of (C89S).UbcH7 was indistinguishable from that of $\mathrm{UbcH} 7$ (Fig. 2b). By immunofluorescence analysis, the GR is expressed principally in the cytoplasm in the absence of ligand (Fig. 2a and b; 0), but almost exclusively in the nucleus in the presence of it (Fig. 2a and b; Dex). The pattern of intranuclear distribution is similar to that we and other researchers, have reported before (Garside et al. 2004). It is clear from the overlapping staining patterns that the site of functional interaction could be either in the cytoplasm or in the nucleus, or both (Fig. 2a and b).

\section{Overexpression of $\mathrm{UbcH} 7$ reduces GR transactivation}

The data presented earlier indicate that $\mathrm{UbcH} 7$ and the GR physically interact within living cells. Consequently, a transient transfection system employing a glucocorticoid sensitive luciferase reporter gene construct was used to examine the functional effects of $\mathrm{UbcH} 7$ on glucocorticoid action. We observed that $\mathrm{UbcH} 7$ inhibited glucocorticoidinduced transactivation of the reporter in a concentrationdependent manner (Fig. 3). It caused both a significant reduction in the maximum activation and a significant increase in the EC50 (Fig. 3).

\section{Inhibition of proteosomal enzymatic activity blocks $\mathrm{UbcH7}$ repression of GR transactivation}

We next determined whether the repressive effect of $\mathrm{UbcH7}$ on dexamethasone-induced transactivation was dependent on the ubiquitin-26S proteasome pathway. As noted earlier (Fig. 3), transactivation was significantly lower when $\mathrm{UbcH} 7$ was overexpressed in COS7 cells (Fig. 4a, compare column 1 with column 2). The UbcH7-mediated inhibition of this transactivation was abolished when cells were cultured in the presence of the $26 \mathrm{~S}$ proteasomal inhibitor, MG132 (Fig. 4a, compare columns 1 and 2 with columns 3 and 4 respectively). Indeed, MG132 enhanced dexamethasone-dependent transactivation in the absence of exogenous $\mathrm{UbcH7}$ (Fig. 4a, (a)

\begin{tabular}{|c|c|c|}
\hline & Ec50 (nM) & $\begin{array}{c}\text { Vmax (fold } \\
\text { induction) }\end{array}$ \\
\hline $\begin{array}{c}0 \mu \mathrm{g} \\
\mathrm{UbcH} 7\end{array}$ & $7.5 \pm 0.8$ & $58 \pm 1.3$ \\
\hline $\begin{array}{c}0.3 \mu \mathrm{g} \\
\mathrm{UbcH7}\end{array}$ & $\begin{array}{c}10 \pm 2 \cdot 4 \\
(P=0.05)\end{array}$ & $\begin{array}{c}48 \pm 2 \cdot 2 \\
(P=0.01)\end{array}$ \\
\hline $\begin{array}{c}1.0 \mu \mathrm{g} \\
\mathrm{UbcH7}\end{array}$ & $\begin{array}{c}13 \pm 1.5 \\
(P=0.02)\end{array}$ & $\begin{array}{c}40 \pm 10 \\
(P=0.003)\end{array}$ \\
\hline
\end{tabular}

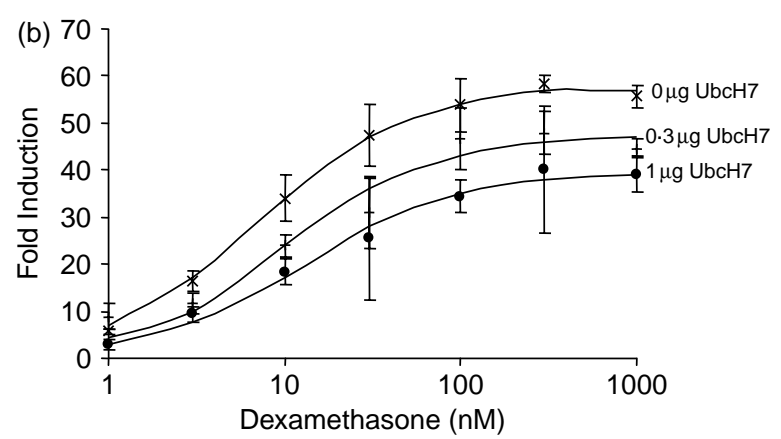

Figure 3 COS7 cells were transiently transfected with MMTV-Luc, pcDNA3-GR, CMV-renilla, UbcH7-GFP, or the empty vector control to keep a constant amount of transfected DNA. Posttransfection cells were treated for $18 \mathrm{~h}$ with a dose-response of dexamethasone (1-1000 nM) in triplicate then lysed and assayed for firefly and renilla luciferase activity. Firefly expression was corrected for renilla luciferase, and expressed as fold induction over a non-treated control. Results representative of three independent experiments are shown as mean \pm S.D. Statistical significance is indicated compared with the empty control vector transfection.

compare column 1 with column 3). These data indicated that protein degradation via the $26 \mathrm{~S}$ proteasome was necessary for repression of GR signaling by $\mathrm{UbcH} 7$.

Further support for this conclusion came from the observation that overexpression of the C89S. $\mathrm{UbcH} 7 \mathrm{domi-}$ nant negative mutant also blocked the inhibition of GR transactivation induced by endogenous $\mathrm{UbcH} 7$ (Fig. 4b, compare column 1 with column 2). There was no additive effect of the MG132 and the dominant negative $\mathrm{UbcH7}$ on glucocorticoid transactivation (Fig. 4b, compare column 2 with column 4).

Transfection of HeLa cells, which express endogenous GR, also showed that $\mathrm{UbcH} 7$ impaired and the dominant negative $\mathrm{UbcH} 7$ enhanced dexamethasone-dependent transactivation (Fig. 5).

\section{Discussion}

To identify novel proteins capable of interacting with the GR C-terminus, a yeast two-hybrid screen was established using RU486 as the ligand. RU486 was selected as it has been shown to recruit co-modulators for GR that are important to function both in the presence of agonists and antagonist, notably NCoR (Stevens et al. 2003a). In this study, we 

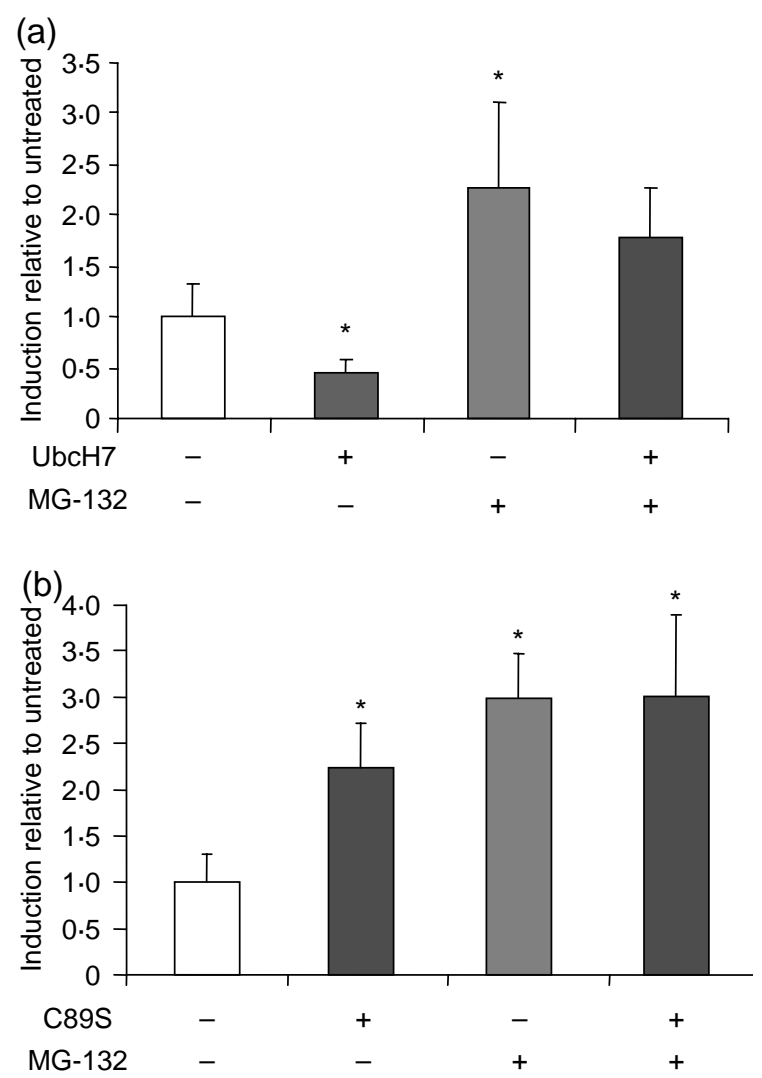

Figure $4 \mathrm{COS} 7$ cells were transiently transfected with MMTV-Luc, pcDNA3-GR, CMV-renilla, UbcH7-GFP, C89S-GFP or the empty vector control to keep a constant amount of transfected DNA. Posttransfection cells were treated for $18 \mathrm{~h}$ with dexamethasone $(100 \mathrm{nM})$, with (+) or without (-) MG-132 in triplicate then lysed and assayed for firefly and renilla luciferase activity. Firefly expression was corrected for renilla luciferase, and expressed as fold induction over a non-treated control. Results representative of three independent experiments are shown as mean \pm s.D. Statistical analysis was performed using ANOVA and Bonferroni $t$-test.

${ }^{*} P<0 \cdot 05$ compared with control (no MG132 or $\mathrm{UbcH7}$ ).

explored the interactions between the GR and $\mathrm{UbcH} 7$, a direct interaction we identified in the yeast two-hybrid screen, and a functional interaction, which has been reported by other groups for the GR and other members of the nuclear receptor superfamily (Verma et al. 2004). Co-immunoprecipitation experiments also identified interaction between GR and endogenous $\mathrm{UbcH} 7$, but only in cells transfected with the dominant negative $\mathrm{UbcH7}$. This may reflect altered stability of the GR or its interactions with other proteins in the absence of authentic $\mathrm{UbcH7}$ activity. For example, UbcH7 has been shown to interact with GR co-modulator proteins, and may be important for stabilizing the GR, or its interactions with $\mathrm{UbcH7}$ (Verma et al. 2004). By inhibiting the enzymatic activity of endogenous $\mathrm{UbcH} 7$ on these partner proteins, the dominant negative $\mathrm{UbcH} 7$ may stabilize interactions between the GR and the UbcH7.

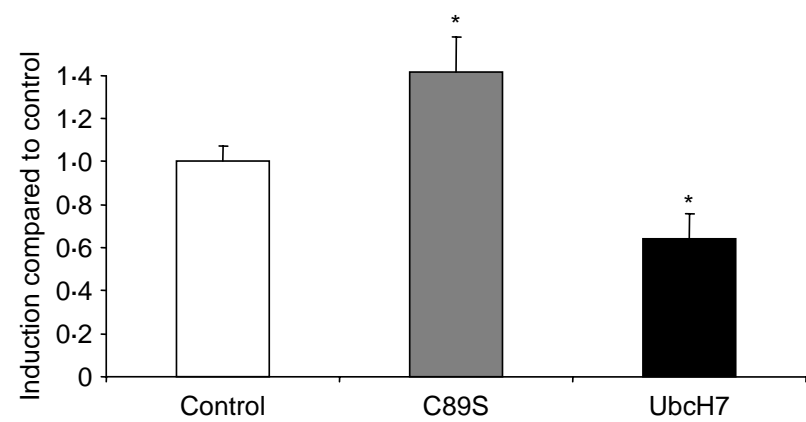

Figure 5 HeLa cells were transiently transfected with MMTV-Luc, CMV-renilla, UbcH7-GFP, C89S-GFP or the empty vector control to keep a constant amount of transfected DNA. Post-transfection cells were treated for $18 \mathrm{~h}$ with dexamethasone $(100 \mathrm{nM}$ in triplicate then lysed and assayed for firefly and renilla luciferase activity). Firefly expression was corrected for renilla luciferase, and expressed as fold induction over a non-treated control. Results representative of three independent experiments are shown as mean \pm s.D. $* P<0 \cdot 05$ compared with control.

Immunofluorescence studies showed co-localisation of GR and $\mathrm{UbcH} 7$ in cells, allowing such interactions to take place. It seems clear that the cytosolic $\mathrm{UbcH} 7$ does not translocate with the GR to the nucleus. The mechanism of interaction between the GR and $\mathrm{UbcH} 7$ remains to be determined, but the related protein, Ubc9, also interacts with the GR C-terminus through an unidentified mechanism (Kaul et al. 2002).

Inhibition of either $\mathrm{UbcH7}$, with dominant negative expression, or of the proteosome, with MG132, potentiated glucocorticoid action. Interestingly, other nuclear receptors, notably estrogen receptor, show the opposite effect, with proteasomal inhibition reducing transactivation (Lonard et al. 2004). Hence, we examined directly the effect of $\mathrm{UbcH} 7$ on GR protein expression levels. These showed that overexpression of dominant negative $\mathrm{UbcH} 7$ resulted in higher GR levels. This further strengthens the conclusion that $\mathrm{UbcH7}$ primarily modifies glucocorticoid sensitivity by regulating glucocorticoid receptor stability in the presence of its ligand. Disruption of this regulatory step, as for example, by overexpression of a dominant negative $\mathrm{UbcH7}$ or inhibition of $26 \mathrm{~S}$ proteasomal activity by MG132 leads to enhancement of glucocorticoid sensitivity. This mechanism is likely to be an important component in the autoregulation of GR expression as $\mathrm{UbcH7}$ expression is ubiquitous and may, therefore, modulate glucocorticoid sensitivity throughout the body.

Whether $\mathrm{UbcH} 7$ acts independent of other factors such as E3s in mediating the downregulation remains to be determined. There may be redundancy in the targeting process as E3s, CHIP, E6-AP, and hmdm2 also interact with the GR (Connell et al. 2001, Sengupta \& Wasylyk 2001, Wallace \& Cidlowski 2001, Nawaz \& O'Malley 2004). The choice of E3 may be dependent on cell type, and indeed, there is evidence that CHIP may contribute not only to the ligand-dependent degradation of GR via the proteasome, but 
also to transactivation, with overexpression of CHIP reversing the potentiation of transactivation seen with MG132 (Wang \& DeFranco 2005). As the GR dissociates from the heatshock protein complex, it exposes new surfaces. Its conformation, particularly in the C-terminal ligand-binding domain, changes markedly to allow effective recruitment of co-modulator proteins (Stevens et al. 2003a). In addition, the $N$-terminal region becomes hyperphosphorylated. One or more of these changes could provide a signal for ubiquitylation.

Regulation of GR expression is a key determinant for cell and tissue glucocorticoid sensitivity. There is clearly a complex relationship between GR and its targeting by the ubiquitin system, as evidenced by our studies presented here, and those recently published (Verma et al. 2004, Wang \& DeFranco 2005). As the dominant negative $\mathrm{UbcH7}$ appears to enhance GR protein concentration, this suggests that $\mathrm{UbcH7}$ acts to suppress such expression in vivo. Whether this modulation of GR protein expression is sufficient to completely explain the actions of $\mathrm{UbcH7}$ is called into question by the findings of Verma et al. (2004). However, we have demonstrated direct interaction between GR and $\mathrm{UbcH7}$, and showed that proteosomal activity is important for the UbcH7 effect, whereas earlier work showed interaction between $\mathrm{UbcH} 7$ and SRC-1 that resulted in UbcH7 potentiating GR transactivation, essentially the opposite result to those presented here (Verma et al. 2004). Therefore, it is possible that $\mathrm{UbcH} 7$ is acting both directly on the GR to mediate degradation, and also on SRC-1 to enhance transactivation. If so, the relative expression of GR, co-activator, or E3 (for example, CHIP; Wang \& DeFranco 2005) may be critical for determining whether $\mathrm{UbcH} 7$ enhances or diminishes GR transactivation. It is also possible that the degree of ubiquitylation is important. For example, monoubiquitylation may be required for transactivation, but once transcription is triggered then polyubiquitylation and proteasomal degradation of the GR may follow. Indeed, there is evidence that the GR contains multiple ubiquitylation sites, but quantification of levels of ubiquitylation has proved difficult (Wallace \& Cidlowski 2001). Extending our studies to HeLa cells, those used in the Verma study, showed similar effects of the $\mathrm{UbcH7}$ overexpression to those found in COS cells. Taken together, our results and those of Verma et al. (2004) show that UbcH7 influences GR transactivation but other factors, as has previously been shown for the E3, CHIP, may determine the magnitude and direction of such change. UbcH7 acts on multiple proteins in the assembly of the GR-catalyzed transcription regulatory complex, and interactions between GR and $\mathrm{UbcH7}$ are likely to be of low affinity, and transitory, as evidenced by co-immunoprecipitation studies. Therefore, the net result of altered $\mathrm{UbcH7}$ on transactivation is likely to be dependent on the expression levels of GR, and multiple co-modulator proteins, including SRC-1 (Kaul et al. 2002, Verma et al. 2004).

Modulation of GR expression levels, particularly in response to agonist ligand, plays an important role in determining glucocorticoid sensitivity. Aberrant regulation of these key enzymatic steps may explain pathological alterations in glucocorticoid sensitivity such as those found within sites of inflammation. In addition, the divergent effects of $\mathrm{UbcH} 7$ on different members of the nuclear receptor super family with considerable structural homology has implications for understanding underlying differences in the mode of action of these related ligand-activated transcription factors.

\section{Acknowledgements}

Supported by BBSRC, Glaxo SmithKline, and The Wellcome Trust. The authors declare that there is no conflict of interest that would prejudice the impartiality of this scientific work.

\section{References}

Ardley HC, Tan NG, Rose SA, Markham AF \& Robinson PA 2001 Features of the parkin/ariadne-like ubiquitin ligase, HHARI, that regulate its interaction with the ubiquitin-conjugating enzyme, Ubch7. Journal of Biological Chemistry 276 19640-19647.

Ardley HC, Scott GB, Rose SA, Tan NG, Markham AF \& Robinson PA 2003 Inhibition of proteasomal activity causes inclusion formation in neuronal and non-neuronal cells overexpressing Parkin. Molecular Biology of the Cell 14 4541-4556.

Bodwell JE, Webster JC, Jewell CM, Cidlowski JA, Hu JM \& Munck A 1998 Glucocorticoid receptor phosphorylation: overview, function and cell cycle-dependence. Journal of Steroid Biochemistry and Molecular Biology 65 91-99.

Cidlowski JA \& Cidlowski NB 1981 Glucocorticoid effects on HeLa S3 cell growth and thymidine incorporation. Cancer Research 41 2687-2691.

Connell P, Ballinger CA, Jiang J, Wu Y, Thompson LJ, Hohfeld J \& Patterson C 2001 The co-chaperone CHIP regulates protein triage decisions mediated by heat-shock proteins. Nature Cell Biology 3 93-96.

Dace A, Zhao L, Park KS, Furuno T, Takamura N, Nakanishi M, West BL, Hanover JA \& Cheng S 2000 Hormone binding induces rapid proteasomemediated degradation of thyroid hormone receptors. PNAS 97 8985-8990.

Deroo BJ, Rentsch C, Sampath S, Young J, DeFranco DB \& Archer TK 2002 Proteasomal inhibition enhances glucocorticoid receptor transactivation and alters its subnuclear trafficking. Molecular and Cellular Biology 22 4113-4123.

Dong Y, Poellinger L, Gustafsson JA \& Okret S 1988 Regulation of glucocorticoid receptor expression: evidence for transcriptional and posttranslational mechanisms. Molecular Endocrinology 2 1256-1264.

Fuchs SY, Fried VA \& Ronai Z 1998 Stress-activated kinases regulate protein stability. Oncogene 17 1483-1490.

Garside H, Stevens A, Farrow S, Normand C, Houle B, Berry A, Maschera B \& Ray D 2004 Glucocorticoid ligands specify different interactions with NF-kappaB by allosteric effects on the glucocorticoid receptor DNA binding domain. Journal of Biological Chemistry 279 50050-50059.

Hoeck W, Rusconi S \& Groner B 1989 Down-regulation and phosphorylation of glucocorticoid receptors in cultured cells. Investigations with a monospecific antiserum against a bacterially expressed receptor fragment. Journal of Biological Chemistry 264 14396-14402.

Kaul S, Blackford JA Jr, Cho S \& Simons SS Jr 2002 Ubc9 is a novel modulator of the induction properties of glucocorticoid receptors. Journal of Biological Chemistry 277 12541-12549.

Kornitzer D \& Ciechanover A 2000 Modes of regulation of ubiquitinmediated protein degradation. Journal of Cellular Physiology 182 1-11. 
Lonard DM, Tsai SY \& O'Malley BW 2004 Selective estrogen receptor modulators 4-hydroxytamoxifen and raloxifene impact the stability and function of SRC-1 and SRC-3 coactivator proteins. Molecular and Cellular Biology 24 14-24.

McIntyre WR \& Samuels HH 1985 Triamcinolone acetonide regulates glucocorticoid-receptor levels by decreasing the half-life of the activated nuclear-receptor form. Journal of Biological Chemistry $260418-427$.

Nawaz Z \& O'Malley BW 2004 Urban renewal in the nucleus: is protein turnover by proteasomes absolutely required for nuclear receptor-regulated transcription? Molecular Endocrinology 18 493-499.

Oakley RH \& Cidlowski JA 1993 Homologous down regulation of the glucocorticoid receptor: the molecular machinery. Critical Reviews in Eukaryotic Gene Expression 3 63-88.

Perissi V, Aggarwal A, Glass CK, Rose DW \& Rosenfeld MG 2004 A corepressor/coactivator exchange complex required for transcriptional activation by nuclear receptors and other regulated transcription factors. Cell 116 511-526.

Sengupta S \& Wasylyk B 2001 Ligand-dependent interaction of the glucocorticoid receptor with p53 enhances their degradation by $\mathrm{Hdm} 2$. Genes and Development 15 2367-2380.

Silva CM, Powell-Oliver FE, Jewell CM, Sar M, Allgood VE \& Cidlowski JA 1994 Regulation of the human glucocorticoid receptor by long-term and chronic treatment with glucocorticoid. Steroids 59 436-442.

Stevens A, Garside H, Berry A, Waters C, White A \& Ray D 2003 a Dissociation of steroid receptor coactivator 1 and nuclear receptor corepressor recruitment to the human glucocorticoid receptor by modification of the ligand-receptor interface: the role of tyrosine 735 . Molecular Endocrinology 17 845-859.

Stevens A, Soden J, Brenchley PE, Ralph S \& Ray DW 2003b Haplotype analysis of the polymorphic human vascular endothelial growth factor gene promoter. Cancer Research 63 812-816.

Svec F \& Rudis M 1981 Glucocorticoids regulate the glucocorticoid receptor in the AtT-20 cell. Journal of Biological Chemistry 256 5984-5987.
Vanderbilt JN, Miesfeld R, Maler BA \& Yamamoto KR 1987 Intracellular receptor concentration limits glucocorticoid-dependent enhancer activity. Molecular Endocrinology 1 68-74.

Vedeckis WV, Ali M \& Allen HR 1989 Regulation of glucocorticoid receptor protein and mRNA levels. Cancer Research 49 2295s-2302s.

Verma S, Ismail A, Gao X, Fu G, Li X, O’Malley BW \& Nawaz Z 2004 The ubiquitin-conjugating enzyme $\mathrm{UBCH} 7$ acts as a coactivator for steroid hormone receptors. Molecular and Cellular Biology 24 8716-8726.

Wallace AD \& Cidlowski JA 2001 Proteasome-mediated glucocorticoid receptor degradation restricts transcriptional signaling by glucocorticoids. Journal of Biological Chemistry 276 42714-42721.

Wang X \& DeFranco DB 2005 Alternative effects of the ubiquitin-proteasome pathway on glucocorticoid receptor down-regulation and transactivation are mediated by CHIP, an E3 ligase. Molecular Endocrinology 19 1474-1482.

Waters CE, Stevens A, White A \& Ray DW 2004 Analysis of co-factor function in a glucocorticoid-resistant small cell carcinoma cell line. Journal of Endocrinology 183 375-383.

Webster JC, Jewell CM, Bodwell JE, Munck A, Sar M \& Cidlowski JA 1997 Mouse glucocorticoid receptor phosphorylation status influences multiple functions of the receptor protein. Journal of Biological Chemistry 272 9287-9293.

Weigel NL 1996 Steroid hormone receptors and their regulation by phosphorylation. Biochemical Journal 319 657-667.

Received 8 February 2006

Received in final form 19 May 2006

Accepted 20 June 2006

Made available online as an Accepted Preprint

14 July 2006 